\title{
AN INVESTIGATION INTO THE ROLE OF INTENTIONS AS MEDIATORS OF THE ATTITUDE-BEHAVIOR RELATIONSHIP *
}

\author{
Richard P. BAGOZZI
}

The University of Michigan, Ann Arbor, USA

\section{Johann BAUMGARTNER}

The Pennsylvania State University, University Park, USA

Youjae YI

The University of Michigan, Ann Arbor, USA

Received July 7, 1988; accepted January 20, 1989

Do intentions mediate all of the effects of attitudes on behavior? This study shows that discovery of the role of intentions depends on the statistical power of test procedures, the reliability of measures of intentions, and the nature of the processes intervening between intentions and behavior.

\section{Introduction}

Many theories of consumer behavior posit that intentions serve as key mediators of the attitude-behavior relation (e.g., Engel et al. 1978; Howard 1977; Foxall 1984). This is consistent with the theory of reasoned action, a well-known theory in psychology (e.g., Ajzen and Fishbein 1980; Verhallen and Pieters 1984). Indeed, Ajzen and Fishbein (1980: 5) maintain that attitudes influence behavior only through their impact on intentions, which Bettman (1986: 268) has termed the 'sufficiency assumption'.

* Requests for reprints should be sent to R.P. Bagozzi, School of Business Administration, The University of Michigan, Ann Arbor, MI 48109-1234, USA. 
Recently, researchers have discovered that attitudes can influence behavior directly, as well as indirectly through intentions (e.g., Bentler and Speckart 1979, 1981). However, other than demonstrating that such effects occur empirically, researchers have not explained why such processes come about.

The questions addressed in the present research are the following. Are the effects of attitudes on behavior mediated fully by intentions or may attitudes influence behavior separately from their effects on intentions? Under what conditions might one find direct effects of attitudes on behavior? What factors might lead one to fail to detect a direct effect when it really exists?

Determining the role of intentions in the attitude-behavior relation is important for a number of reasons. One of these is both conceptual and philosophical. How can an attitude, a mental event, influence behavior, an observable action? Ajzen and Fishbein (1980) apparently answer this question by postulating that an intention, a particular type of volition, transforms the psychological state into guided bodily responses. Although the exact nature of the transformational process remains little understood, at least to date, the postulation of such a process overcomes one serious drawback with acceptance of a direct path from attitudes to behavior in the theory of reasoned action. Namely, it seems unreasonable to maintain that attitudes automatically stimulate action, as a direct path implies. Rather, for attitudes to cause behavior, one must decide or intend to perform the behavior. After all, we may have a positive attitude toward performing some act but fail to form an intention or intend to refrain from doing the action because of some nonattitudinal reason. Including a direct path from attitude to behavior does not allow for such possibilities.

This is not to say that attitudes can only affect behavior indirectly through intentions. Indeed, attitudes might at times stimulate an action with little or no thought, such as occurs in impluse buying, routine response behavior, or purchases made in response to compelling emotional pressures. Nevertheless, under such conditions, it might be maintained that behavior is not fully under volitional control in the sense implied by so-called rational theories such as the theory of reasoned action.

Thus, we take the position that the impact of attitudes on behavior occurs as either a reasoned process operating through intentions or an unreasoned one operating directly on behavior, but not both. Concep- 
tually, this appears to be consistent with the meaning of the terms in the theory and in everyday usage (cf. Ajzen 1985). Webster's New Collegiate Dictionary (1980) defines intention as, 'a determination to act in a certain way' and to intend as 'to have in mind as a purpose or goal' (p. 596). Synonyms of intention include 'intent, purpose, design, aim, end, objective, goal' (Webster's New Collegiate Dictionary 1980: 596) and 'deliberateness, calculation, willingness, determination' (Roget's Thesaurus 1966: 361). The shared meaning throughout these synonyms of intention seems to be 'what one purposes to accomplish or attain' (Webster's New Collegiate Dictionary 1980: 596). But attitude-stimulated actions out of impluse or in response to intense emotional pressure do not involve purposeful elements in these senses. It is unlikely for an action to be both purposeful and nonpurposeful in the same instance. Hence, we feel that attitudes influence behavior either directly as a nonpurposeful reaction or indirectly through intentions as a purposeful response.

Another reason for being concerned about the role of intentions in the attitude-behavior relation is practical. If intentions are found to fully mediate the effect of attitudes on behavior, communication strategies must take into account the nature and timing of intention formation if they are to lead to behavior change. On the other hand, if intentions are found not to mediate the effect of attitudes or do so only in a partial sense, then consideration might be given to nonrational or nonvolitional strategies for bringing about behavior change. For instance, persuasive tactics might be aimed at inducing strong affect with the hope that behavior will be activated in a more or less automatic way. In either of the aforementioned cases, the role of intentions must be known if one is to design a communication program effectively and efficiently.

Despite the importance of intentions in decision making, extant research on the issue is inconclusive. Indeed, as outlined hereafter, we point out that several conceptual and methodological problems might lead researchers to make either type I or type II errors when interpreting findings. The goal of this study is therefore to critically review the relevant findings, identify potential difficulties that may have precipitated false conclusions, and conduct a series of studies that rectify these potential threats to validity.

The paper is organized as follows. We begin with an analysis of findings in the psychology and consumer behavior literatures dealing 
with the role of intentions in the attitude-behavior relation. By and large, the findings will be shown to be equivocal because of certain conceptual and methodological problems of the studies. Next, we present a series of three studies designed to shed new light on the functioning of intentions by exploring the consequences of these problems. Study 1 reveals that low statistical power serves as a rival hypothesis for those studies in the literature supporting a role for intentions fully mediating the effects of attitudes. Study 2 demonstrates that the reliability of intention measures and the occurrence of psychological processes between the formation of intentions and the performance of a behavior affect the test of hypotheses. Study 3 investigates the operation of intentions when statistical power, reliability, and intervening processes are all taken into account.

\section{Recent findings}

Eleven studies could be found in the social psychology and consumer behavior literature that bear upon the mediating role of intentions. ${ }^{1}$ These studies addressed 15 behaviors, and relevant findings are summarized in Table 1. As can be seen under the first column of the table, a positive direct effect was found for seven behaviors, a negative direct effect for one, and no significant direct effect for seven. On balance, then, the evidence indicates that a direct effect from attitudes to behaviors is possible at times. Nevertheless, the findings from these studies should be taken as inconclusive for a number of reasons. For purposes of discussion, we present these reasons in the following order: volitional control, statistical power, reliability of intentions, and correspondence between intentions and behavior. Following these, we ad-

1 The attitude literature contains many hundreds of investigations and extends back over fifty years. Most of the studies focus either on attitude measurement, the attitude-intention relation, the intention-behavior relation, or the attitude-behavior relation. For example, most studies reviewed by Ajzen and Fishbein (1977) focus on the attitude-behavior relation, whereas many studies reported by Belk (1985) examine the intention-behavior correlation. Very few studies contain measures of attitudes, intentions, and the behavior; among these, the practice has frequently been to test only the direct paths implied by the theory of reasoned action or similar models. The eleven studies reviewed herein constitute all those we could find in the social psychology and consumer behavior literature over the past decade which not only had measures of attitudes, intentions, and behavion but also perfonmed tests of both dinect and indirect effects of attitudes on behavior. 
Table 1

Comparison of results from eleven studies examining the mediating role of intentions in the attitude-behavior relationship.

\begin{tabular}{|c|c|c|c|}
\hline \multirow[t]{2}{*}{ Study } & \multicolumn{3}{|c|}{ Standardized regression weights } \\
\hline & $\begin{array}{l}\text { Attitude } \\
\rightarrow \text { behavior }\end{array}$ & $\begin{array}{l}\text { Intention } \\
\rightarrow \text { behavior }\end{array}$ & $\begin{array}{l}\text { Attitude } \\
\rightarrow \text { intention }\end{array}$ \\
\hline Zuckerman and Reis (1978) & & & \\
\hline $\begin{array}{l}\text { Blood donation: } \\
\text { - full sample } \\
\text { - reduced sample }\end{array}$ & $\begin{array}{l}0.15^{\mathrm{a}} \\
0.20^{\mathrm{b}}\end{array}$ & $\begin{array}{l}0.34^{\mathrm{c}} \\
0.36^{\mathrm{c}}\end{array}$ & $\begin{array}{l}0.32^{\circ} \\
0.40^{\mathrm{c}}\end{array}$ \\
\hline $\begin{array}{l}\text { Bentler and Speckart (1979) } \\
\text { Consumption of } \\
\text { - alcohol } \\
\text { - marijuana } \\
\text { - hard drugs }\end{array}$ & $\begin{array}{l}0.40^{\mathrm{c}} \\
0.50^{\mathrm{c}} \\
0.51^{\mathrm{c}}\end{array}$ & $\begin{array}{l}0.43^{\mathrm{c}} \\
0.33^{\mathrm{c}} \\
0.14\end{array}$ & $\begin{array}{l}0.55^{\mathrm{c}} \\
0.80^{\mathrm{c}} \\
0.42^{\mathrm{c}}\end{array}$ \\
\hline $\begin{array}{l}\text { Bentler and Speckart (1981) } \\
\text { Dating } \\
\text { Studying } \\
\text { Exercise }\end{array}$ & $\begin{array}{r}-0.47 \\
-0.22^{a} \\
0.65^{a}\end{array}$ & $\begin{array}{l}0.93^{\mathrm{a}} \\
0.30^{\mathrm{b}} \\
0.09^{-}\end{array}$ & $\begin{array}{l}0.85^{\mathrm{c}} \\
0.04 \\
0.92^{\mathrm{c}}\end{array}$ \\
\hline $\begin{array}{l}\text { Bagozzi (1981) } \\
\text { Blood donation: } \\
\text { attitude toward act } \\
\text { - proximal behavior } \\
\text { - distal behavior } \\
\text { expectancy-value attitude } \\
\text { - proximal behavior } \\
\text { - distal behavior }\end{array}$ & $\begin{array}{r}0.00 \\
0.08 \\
-0.14 \\
0.02\end{array}$ & $\begin{array}{l}0.45^{\mathrm{c}} \\
0.02^{2} \\
0.51^{\mathrm{c}} \\
0.03^{\mathrm{N}}\end{array}$ & $0.45^{\mathrm{c}}$ \\
\hline $\begin{array}{l}\text { Fredricks and Dossett (1983) } \\
\text { Class attendance }\end{array}$ & 0.03 & 0.09 & $0.36^{b}$ \\
\hline $\begin{array}{l}\text { Manstead et al. (1983) } \\
\text { Infant feeding }\end{array}$ & $0.15^{b}$ & $0.71^{\mathrm{c}}$ & $0.57^{\mathrm{c}}$ \\
\hline $\begin{array}{l}\text { Bonfield (1974) } \\
\text { Fruit drinks }\end{array}$ & $0.22^{b}$ & $0.29^{c}$ & 0.05 \\
\hline $\begin{array}{l}\text { Oliver and Berger (1979) } \\
\text { Flu vaccinations }\end{array}$ & & & \\
\hline $\begin{array}{r}- \text { sample } 1 \\
\text { sample } 2\end{array}$ & $\begin{array}{r}-0.06 \\
0.01\end{array}$ & $\begin{array}{l}0.26^{b} \\
0.32^{b}\end{array}$ & $\begin{array}{l}0.49^{b} \\
0.53^{b}\end{array}$ \\
\hline $\begin{array}{l}\text { Ryan and Bonfield (1980) } \\
\text { Loan applications }\end{array}$ & 0.13 & $0.27^{\mathrm{b}}$ & $0.34^{\mathrm{c}}$ \\
\hline $\begin{array}{l}\text { Bagozzi (1982) } \\
\text { Blood donation }\end{array}$ & -0.05 & $0.32^{b}$ & $0.33^{a}$ \\
\hline $\begin{array}{l}\text { Shimp and Kavas (1984) } \\
\text { Coupon usage }\end{array}$ & 0.01 & $0.68^{b}$ & $0.34^{b}$ \\
\hline
\end{tabular}

a $p \leq 0.05 ;{ }^{\text {b }} p<0.01 ; \quad$ c $p<0.001$. 
dress two additional problems - discriminant validity and demand characteristics - peculiar to two particular studies.

Volitional control. It is unclear whether all actions were under volitional control in the studies summarized in table 1 , a requirement put forth by Ajzen and Fishbein (1980: 5). Indeed, in three cases (i.e., hard drug usage, exercising, class attendance), intentions failed to significantly predict behaviors at all (see table 1, column 2). And for three other behaviors (i.e., alcohol, marijuana usage, and fruit drinks), it can be argued that habitual or physiological factors were prepotent. Notice that, for these actions, a considerable portion of the variance in behavior is accounted for by attitudes directly, lending support to the conclusion of a reduced role for volitions (see relative magnitude of weights in columns 1 and 2 in table 1). Similarly, when past behavior was included as a predictor of behavior in the investigations of alcohol and marijuana usage (Bentler and Speckart 1979), the effects of past behavior were all larger than those of intentions (not shown in table 1). This also suggests that these behaviors were under more habitual than volitional control. At the same time, it is difficult to explain the counter-intuitive negative, direct effect of attitudes on behavior for studying (Bentler and Speckart 1981). This occurred despite positive effects of intentions on behavior. However, attitudes did not significantly predict intentions. To the extent that each of the aforementioned behaviors exhibited mindless (Langer 1978), scripted (Abelson 1981), habitual (Landis et al. 1978), and/or learned or biological components, one would expect less of a role for volitional determinants.

Statistical power. Findings of nonsignificant direct effects of attitudes on behavior are equally inconclusive unless the power of the statistical procedures is adequate for detecting such paths at acceptable levels of significance. None of the studies presented information bearing on the power of their analyses for detecting the focal direct path, however. Statistical power is most likely not an issue for the nonsignificant direct path for dating in Bentler and Speckart (1981) because significant direct paths were found using similar procedures and the same respondents for exercise and studying in their investigation. We will provide a more detailed discussion on power under Method in study 1 . 
Reliability of intention measures. Another factor concerns the reliability of the measures of intentions. ${ }^{2}$ To the extent that random error exists in the intention measures, the coefficient relating intentions to behavior will be underestimated. It is conceivable that the nonsignificant paths found for the effects of intentions on behavior noted in table 1 resulted from attenuation due to random error. Similarly, it is possible that the findings of direct paths from attitudes to behavior reflect inflation factors due to the unreliability in measures of intentions. Poor measures of intentions reduce the likelihood that a test will reveal that intentions channel the impact of attitudes on behavior and at the same time weaken the ability of intentions to serve as effective covariates in the equation regressing behavior on attitudes and intentions. Because many of the studies listed in table 1 used single measures for intentions, it is not possible to rule out such potentialities.

Correspondence between intention and behavior measures. Still another issue we wish to raise is the need to conceptualize and measure behaviors most directly connected to intentions in an etiological sense. Many actions, call them target behaviors, are dependent on one or more instrumental acts for their completion (c.f., Verhallen and Pieters 1984). For example, actual purchase of brand $X$ often is the result of the prior activity of making a shopping list for tomorrow's groceries. In this instance, the intention to purchase brand $X$ leads to a plan and writing of that plan and this, in turn, is a precursor to actual purchase. Tests of hypotheses involving an inappropriate act in a chain of behaviors could obscure or bias one's ability to infer the mediating role of intentions, depending on the particular causal processes involved. A valid direct path from attitudes to an instrumental act, for example, might be overlooked if the wrong behavior later in the sequence were erroneously substituted for the focal act.

Discriminant validity. One might also question the validity of the findings for a direct causal path in Manstead et al. (1983). We believe that discriminant validity is lacking among their measures of behavior,

${ }^{2}$ It should noted that reliability of measures is important for all key constructs (e.g., attitude and behavior), but intention measures are primarily examined in this study, because our focus is on the role of intentions. Reliabilities of other constructs are taken into account by correcting for attenuation with multiple measures. 


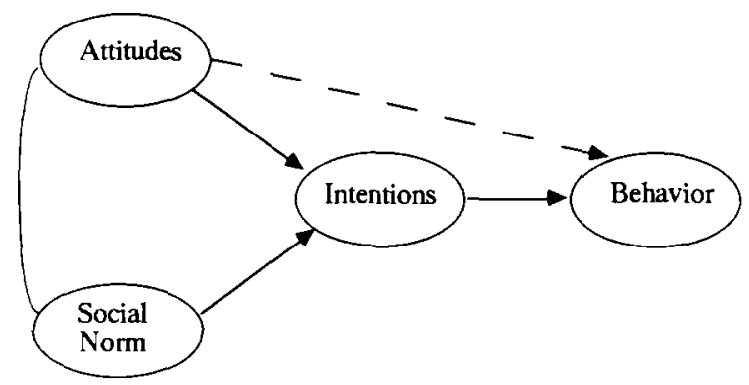

Fig. 1. Causal model used to investigate statistical power in studies 1 and 2 (only latent variables are shown for simplicity).

intentions, and attitudes. ${ }^{3}$ To determine this, we tested three models on their data by use of LISREL (Jöreskog and Sörbom 1984). Although our test of the models presented in fig. 1 indicated an adequate fit $\left(\chi^{2}=0.11, d f, p \cong 0.75\right)$ and the direct path from attitude to behavior was indeed significant as Manstead et al. maintained $\left(\chi_{d}^{2}=7.25,1 d f\right.$, $p<0.001)$, the findings for two rival models - \#1( $\chi^{2}=2.75,1 d f$, $p \simeq 0.10)$ and $\# 2\left(\chi^{2}=3.02,2 d f, p \simeq 0.22\right)$ - also demonstrate adequate fits. Rival model $\# 1$ hypothesizes that intentions and behavior measure the same latent variable and hence fail to show discriminant validity. Rival model \#2 hypothesizes that attitudes, intentions, and behavior measure a common latent variable and thus fail to yield discriminant validity. Based on our inability to distinguish among these models, one must question the evidence for a causal link, direct or otherwise, between attitudes and behavior.

Demand characteristics. Some equivocality exists in the interpretation of a direct path as well in the study by Zuckerman and Reis (1978). It

3 The zero-order correlations among the focal measures in Manstead et al. (1983: 662) were

(1) Behavior

(2) Intentions

(3) Differential attitudes

(4) Differential subjective norms

\section{(1)}

(2) 1.00

0.82

0.67

0.49
(3)

(4)

1.00

0.73

0.60

1.00

0.49

1.00

with $n=215$. Notice that the correlations anong belavior, intentions, and altitudes are both large and relatively close in magnitudes. 
might be argued that administering a questionnaire on blood donation to students, asking them to sign their names, and the concomittant placing of posters 'in the two lecture halls where their [the students'] courses were taught' (Zuckerman and Reis 1978: 501) introduced demand characteristics. For example, by making attitudes and related responses salient, the research design may have led people to focus on the degree of correspondence between their attitudes and past behavior. Subsequent exposure to posters asking one to donate blood may have stimulated giving by some respondents more as a consequence of the comparison of attitudes to past behavior than as a result of a decision to give based on a weighing of the pros and cons (e.g., one's expectancy-value attitudes). This would tend to inflate the direct attitude-behavior relation. As a matter of fact, the results showed that respondents gave blood at a rate $214 \%$ greater than the student body rate, suggesting perhaps the operation of an unmeasured confound (Zuckerman and Reis 1978: 503).

In summary, the existing findings in both psychological and consumer research are mixed as to the validity of the direct path from attitudes to behavior. Some studies have found a significant direct effect, whereas others have not. As our analyses revealed, certain problems or limitations could be found in many of the studies, resulting in the conclusion that the empirical evidence is inconclusive. The findings showing or failing to show a significant direct path from attitudes to intentions could have occurred because of the difficulties noted heretofore, rather than because a direct path did or did not in truth exist. The three studies presented hereafter attempt to formally explore the effects of the methodological problems and conduct tests not contaminated by them.

\section{The present studies}

The major goal of our studies is to explore certain conditions under which one may conclude that intentions do or do not mediate the effects of attitudes on behavior. In study 1 , we assess whether the statistical power of the procedures used by previous researchers who found no direct paths from attitudes to hehavior was sufficient to confidently conclude that intentions indeed mediated all the effects of 
attitudes on behavior. This will involve a reanalysis of the data from the relevant studies using procedures recently proposed in the psychometric literature for computing statistical power (e.g., Satorra and Saris 1985). In study 2, we examine two additional factors affecting the ability of intentions to mediate the attitude-behavior relation: namely, (a) the reliability of the intention measures, and (b) the specification of the nomological network between intentions and target behavior. Building on the findings in studies 1 and 2, study 3 then provides a test of the ability of intentions to mediate the impact of attitude on behavior when statistical power, reliability, and specification issues are considered.

\section{Study 1}

Among the eleven studies reviewed in table 1, six provide clear support for the contention that intentions mediate all the effects of attitude on behavior. ${ }^{4}$ However, the question remains whether these findings actually support the classic sequence or whether the failures to detect direct paths from attitudes to behavior could have been due to a lack of statistical power. To determine this, we reanalyzed the data from the six studies that found the attitude-behavior link to be nonsignificant and computed the power of the statistical procedures to detect the direct attitude-behavior path. ${ }^{5}$ For comparison purposes, the theory of reasoned action was chosen as the model under scrutiny in each data set (see fig. 1). ${ }^{6}$

\section{Method}

To place the issue of statistical power in pcrspective as it applies in in study 1 , we offer the following interpretation. The null hypothesis we

\footnotetext{
4 Although Fredricks and Dossett (1983: 507) found that intentions failed to predict behavior in their main models, intentions did significantly predict behavior in their test of the theory of reasoned action.

5 The authors wish to thank the following Professors for access to the data reanalyzed in this study: Richard L. Oliver, Michael J. Ryan, Terrence A. Shimp, and Paul R. Warshaw.

6 The findings did not change appreciably when the power tests were performed on the expanded model of fig. 1 which included past behavior as an exogenous variable in those studies including relevant tuedsures. The expanded model was suggested by Bentler and Speckart (1979: 455) and is consistent with theorizing by Triandis (1977) on the role of habit.
} 
wish to examine is the prediction that no direct causal relation exists between attitudes and behavior (see the dashed arrow in fig. 1). By power in this context, we mean the probability that a statistical test will correctly reject the null hypothesis. The probability that the test will incorrectly fail to reject the null hypothesis (i.e., the type II error rate) is equal to $(1-$ power).

If we find that the direct path from attitudes to behavior is nonsignificant, then two possibilities exist. Either the causal path does not exist or our test is not sensitive enough to detect a causal path that actually does exist. For a statistical test with low power, the latter conclusion is quite likely. 'I hat is, the test leads to an incorrect conclusion of nonsignificance for the causal path from attitudes to behavior and we will have made a type II error. A rejection of the null hypothesis is unlikely even when the null hypothesis is false. Hence, our confidence is weak that no direct causal path exists. On the other hand, when the statistical power is high, the test is sensitive to detect a causal path that actually exists. If a direct path is not detected under these circumstances, we may conclude that the presence of such a path in this particular instance is unlikely.

We used the procedure developed by Saris for determining the power of the chi-square tests under LISREL (Saris and Stronkhorst 1984; Satorra and Saris 1985). In particular, we ascertained the power to detect the presence of a valid direct path from attitudes to behavior. In general the power of any test will be a function of sample size, the level of significance, and the magnitude of the causal path under scrutiny. For our reanalyses, the sample sizes are given. We chose the 0.05 level of significance based on accepted practice in the behavioral sciences. The minimum standardized value for the direct path was chosen to be 0.2 after correction for attenuation due to unreliability in measures. Notice in table 1 that the significant direct paths from attitudes to behavior in those studies correcting for measurement error were greater than 0.2 in all cases, and generally much more so. The 0.15 values found hy Manstead et al. (1983) and by Zuckerman and Reis (1978) and the 0.22 path found by Bonfield (1974) might have been attenuated since they were from analyses where no corrections for measurement error were performed. Thus, a path of 0.2 seems practically justified.

To compute power, the following steps were followed for the reanalyses of each data set (Bagozri and Yi 1988). First, the model in fig. 1 without a direct path from attitudes to behavior was run in order to 
obtain a set of baseline parameter estimates. Next, an analysis was performed of the alternative model represented by the diagram of fig. 1 with the path from attitude to behavior fixed at 0.2 and all other parameters fixed at the values found from the baseline model. This yields a fitted moments matrix which may contain improper solutions (e.g., values in the diagonal smaller than or greater than unity). If improper solutions appear, the alternative model must be rerun by adjusting the corresponding error variances of measures to yield a proper moments matrix. The resulting fitted moments matrix is then used as input in a new analysis of the original model in fig. 1 without a direct path from attitudes to behavior. The resulting chi-square values are the noncentrality parameters which indicate the shift in the chisquare distribution due to the error in specification (i.e., the modeling of no path from attitudes to behavior when in fact the path is 0.2 ). Finally, the power of the test can be found by inspection of appropriate noncentral chi-square tables, given the degrees of freedom for the model, the value of the noncentrality parameter, and $\alpha=0.05$.

\section{Results and Discussion}

The results show that the power was 0.15 in Bagozzi (1981); 0.12 in Fredricks and Dossett (1983); 0.87 and 0.75 for samples 1 and 2, respectively, in Oliver and Berger (1979); 0.50 in Ryan and Bonfield (1980); 0.15 in Bagozzi (1982); and 0.29 in Shimp and Kavas (1984). The sample sizes for these respective studies were 95, 236, 469, 323, 93, 95, and 533. Overall, the findings suggest that test procedures of these studies were not statistically powerful enough to detect a direct, if any, path from attitude to behavior, except for Oliver and Berger's (1979) study.

In sum, although six studies found that attitudes do not directly influence behavior and that intentions fully mediate the attitudebehavior relation, as theory dictates (e.g., Fishbein and Ajzen 1975), we cannot rule out the possibility that a direct path existed but that the procedures used to test hypotheses were not powerful enough to discover such a path in most of these investigations. As a consequence, the findings in Table 1 are equivocal. It has been found that studies failing to find a direct path from attitudes to hehavior lacked the statistical power necessary to confidently support the results. See 
Bagozzi and Yi (1988) for a discussion of the issues in interpreting the findings in terms of statistical power.

\section{Study 2}

\section{Hypotheses}

To explore some of the conditions under which intentions might or might not be found to mediate the effect of attitudes on behavior, we tested two hypotheses. The first concerns the reliability of the measures of intentions. We predict that the more reliable the measures of intentions, the less likely that attitudes will influence behavior directly. We expect to observe that attitudes affect behavior both directly and indirectly when single measures of intentions are used to indicate a latent intention variable but that, when multiple indicators are provided, intentions channel more of the impact of attitudes on behavior. Multiple measures within the context of structural equation models with latent variables permit one to avoid the overly restrictive assumption of perfect reliability required for single indicators and to correct for the attenuation due to unreliability in the indicators. As a consequence, when represented in this way, intentions can function more accurately as a covariate in the regression equation taking behavior as the dependent variable and therefore permit a more valid test of its ability to channel the effects of attitude.

I'he second hypothesis pertains to the nomological network between intentions and behavior. We expect that as the number of instrumental acts between intentions and behavior increases, the less likely attitudes will influence behavior directly. This is because the correspondence between attitude and behavior decreases. In our study, we operationalize the occurrence of instrumental acts with measures of each respondent's self-appraisal of whether or not he or she tried to perform the focal behavior (cf. Verhallen and Pieters 1984). Trying, then, refers to behavioral attempts to perform a target behavior (e.g., doing comparison shopping before making a purchase). It is predicted that direct effects of attitudes on behavior will be more likely for the instrumental act of trying to perform the behavior than for actual performance of the behavior. The rationale is similar to Ajzen and Fishbein's (1977) correspondence hypothesis. The correspondence between attitudes and 
instrumental acts is closer in time and psychological proximity than is the correspondence between attitudes and a target behavior.

\section{Method}

The causal model shown in fig. 1 was used to investigate the two hypotheses. Respondents were 240 undergraduate business students who were asked to provide attitudinal, subjective norm, behavioral expectations, and intentional responses toward both losing weight and initiating a converstation with an attractive stranger. One week later, they were asked whether they had tried to lose weight and initiate a conversation and also whether they actually had lost weight and initiated a conversation with an attractive stranger successfully anytime in the prior week.

Three measures of attitude toward performance of each behavior were taken. Respondents were asked, 'All things considered, my trying to lose weight (initiate a conversation with an attractive stranger) during the next week would make me feel...' Three 7-point bi-polar adjectives describing the respondent's feelings were used: pleasant/ unpleasant, good/bad, and satisfying/unsatisfying. The subjective norm toward trying was measured with the following item: "Most people who are important to me think that I should try to lose weight (initiate a conversation with an attractive stranger) during the next week.' A 7-point likely/unlikely index was used to record responses.

Intentions were elicited with the statements, "I presently intend to try to lose weight (initiate a conversation with an attractive stranger) during the next week.' One measure was a 7-point likely/unlikely index, and the other was an 11-point definitely no/definitely yes index. Likewise, actual trying to lose weight and initiate a conversation were recorded one week hence with yes/no items. Subsequent weight loss and initiation of conversations were elicited through self-reports to appropriate queries.

The program LISREL was again employed to test hypotheses (Jöreskog and Sörbom 1984). Chi-square difference tests were used to examine the significance of the direct paths from attitudes to behavior under the different hypotheses. In addition, the procedure for determining power developed by Saris and Stronkhorst (1984) was again utilized with $\alpha=0.05$ and a 0.2 standardized path value for the attitude-behavior link chosen for the tests. 


\section{Results}

A summary of findings appears in table 2. The first column shows the results for the direct paths from attitudes to behavior. It can be seen that, for trying as the criterion, significant effects result when single measures of intentions are used as operationalizations but nonsignificant direct paths occur when multiple measures of intentions are used. When final behavior is the criterion, the direct path from attitudes to behavior is nonsignificant in each case. The findings in the second column of table 2 indicate that the intentions-behavior relations are significant in all instances, thereby confirming the operation of volitional processes. The third column in table 2 shows that the attitude-intentions relation is significant in each case and thus establishes that attitudes affect intention, according to theory.

Table 2 summarizes the findings for the first hypothesis dealing with reliability of the measures of intentions. Notice first, as hypothesized,

Table 2

Results for evaluating the mediating role of intentions (study 2).

\begin{tabular}{|c|c|c|c|c|c|}
\hline \multirow[t]{2}{*}{ Model } & \multicolumn{3}{|c|}{ Standardized regression weights } & \multicolumn{2}{|c|}{ Test of direct effects } \\
\hline & $\begin{array}{l}\text { Attitude } \\
\rightarrow \text { behavior }\end{array}$ & $\begin{array}{l}\text { Intention } \\
\rightarrow \text { behavior }\end{array}$ & $\begin{array}{l}\text { Attitude } \\
\rightarrow \text { intention }\end{array}$ & $\overline{\chi_{d}^{2} \text {-test }}$ & Power \\
\hline \multicolumn{6}{|l|}{ Trying as criterion } \\
\hline \multicolumn{6}{|l|}{ Losing weight } \\
\hline \multicolumn{6}{|l|}{ - Single measure } \\
\hline of intentions & $0.20^{b}$ & $0.40^{b}$ & $0.51^{\mathrm{b}}$ & $\chi_{d}^{2}(1)=7.66^{\mathrm{b}}$ & 0.56 \\
\hline - Multiple measures & 011 & $051^{b}$ & $055^{b}$ & $x^{2}(1)=237$ & 040 \\
\hline \multicolumn{6}{|c|}{ Initiating a conversation } \\
\hline \multicolumn{6}{|c|}{ - Single measure } \\
\hline of intentions & $0.14^{\mathrm{a}}$ & $0.39^{\mathrm{b}}$ & $0.57^{b}$ & $x_{d}^{2}(1)-3.53^{\mathrm{a}}$ & 0.49 \\
\hline \multicolumn{5}{|l|}{ - Multiple measures } & 0.34 \\
\hline \multicolumn{6}{|c|}{ Target behavior as criterion } \\
\hline \multicolumn{6}{|c|}{ Initiating a conversation } \\
\hline $\begin{array}{l}\text { - Single measure } \\
\text { of intentions }\end{array}$ & 0.03 & $0.49^{b}$ & $0.57^{\mathrm{b}}$ & $\chi_{d}^{2}(1)=0.18$ & 0.53 \\
\hline $\begin{array}{l}\text { - Multiple measures } \\
\text { of intentions }\end{array}$ & -0.07 & $0.60^{b}$ & $0.64^{b}$ & $\chi_{d}^{2}(1)=0.77$ & 0.36 \\
\hline
\end{tabular}

a $p \leq 0.10 ;{ }^{\text {b }} p \leq 0.01$. 
we cannot reject, on the basis of chi-square difference tests, the presence of a direct path from attitudes to behavior, for both losing weight and initiating a conversation, when only a single measure of intentions is employed. In contrast, the direct path from attitudes to behavior is nonsignificant, as predicted, for losing weight and initiating a conversation, on the basis of the chi-square difference tests, when two indicators of intentions are utilized.

Table 2 also presents the results for the nomological network hypothesis. The criterion of actually initiating a conversation is the only target behavior examined for tests of hypotheses. This is because actual weight loss in an outcome, not a behavior, and is not a proper criterion under the theory of reasoned action (Ajzen and Fishbein 1980). Initiating a conversation is, of course, a behavior. As shown in the table, the direct effect from attitudes to behavior is insignificant, according to the hypothesis, whether we measure intentions with one or two measures.

The final findings to note are the statistical power of the tests for detecting a direct path from attitudes to behavior in the final column. The levels of power range from low to moderate values, with most in the moderate range.

\section{Discussion}

The results indicate that a direct path from attitudes to behavior can be found simply as a consequence of unreliability in the measures of intentions. It is obvious in the limit that totally unreliable measures of intentions will suggest a direct path from attitudes to behavior. But not so obvious is the fact that relatively small decrements in reliability can artificially suggest a direct path where none really exists. In our study, intentions mediated all the impact of attitudes on behavior when two indicators of intentions were cmployed. The composite reliability for the two indicators of intentions to lose weight was 0.96 , and the composite reliability for the two indicators of intentions to initiate a conversation was $0.86 .{ }^{7}$ Yet, when only one indicator was used to measure intentions for either criterion, attitudes also directly influenced behavior. ${ }^{8}$ This suggests that the finding of a direct path from atti-

\footnotetext{
7 The composite reliabilities were computed from the standardized factor loadings in the causal models.

8 The results were the same when either measure of intentions was used.
} 
tudes to behavior is sensitive to small, presumably typical, fluctuations in reliability of measures of intentions. A point to stress is that the studies in the literature examining single-act criteria and finding a direct path from attitudes to behavior used single indicators for intentions (see table 1). As a consequence, one cannot rule out the rival hypothesis that excessive measurement error in intentions was the reason for the observed direct effects in these studies. ${ }^{9}$

The findings suggest further that, as one uses as a behavioral criterion measures farther along the chain from instrumental acts to a target behavior, the chances of observing a direct path decrease. Our results showed that one's ability to detect direct paths from attitudes to behavior declined with the length of the path even when we utilized less reliable measures of intentions. Thus, a correct specification of the network of acts between intentions and ultimate behavioral performance is necessary if one is to avoid type I and type II errors in testing the direct path. In our study, the appropriate proximal behavioral criteria were trying to lose weight and trying to initiate a conversation with an attractive stranger. Presumably, not all attempts to perform will be successful, and therefore the correspondence between attitudes and intentions on the one hand and target behavior on the other was less than the correspondence between the same antecedents and the instrumental acts of trying.

To the extent that attempts to perform any behavior will be less than perfectly successful, we would generally expect most tests of the

\footnotetext{
9 We emphasize here that the conclusions apply to investigations performed at the level of single-act criteria. Bentler and Speckart $(1979,1981)$ used three measures of intentions for each criterion in their studies and thus were able to correct for unreliability in the intentions measures. It is important to note, however, that Bentler and Speckart's research was performed at the level of multiple-act criteria. Attitudes, intentions, and behavior were represented as latent constructs each indicated by three distinct instances of the appropriate content domain. For example, attitudes, intentions, and behavior related to dating each had measures pertaining to 'going out on a date', 'visiting a friend of the opposite sex', and 'making out or necking'. Drug use referred to 'downers', 'uppers', and 'other drugs'. Exercise pointed to 'going walking or jogging', 'doing callisthenics or other exercises', and 'getting involved in active sports'. The latent variables concerning multiple-act criteria in these senses are at higher levels of abstraction than the latent variables found for single-act criteria. The psychological and phenomenological meaning of multiple-act and single-act contructs are different and may imply different psychological processes, an issue not considered by researchers heretofore. As a consequence, we believe that it is premature to make claims about the conditions under which attitudes directly affect behavior when multiplc-act critcria arc the object of enquiry. The thcory of reasoncd action is on stronger theoretical footing when applied to single-act criteria.
} 
mediating role of intentions to be biased against discovering a direct effect when the target behavioral performances, rather than the attempts to perform, are used as criteria. Could it be that Fredricks and Dossett's (1983) failure to find a direct path was due to inclusion of individuals in the analyses who intended and/or tried to study but did not (e.g., because of illness, noise distractions, temptations to do other things)? And could Bagozzi's (1981) similar failure to find a direct path be due to the inclusion of respondents in the sample who intended and/or tried to give blood but did not (e.g., due to being underweight, sick, or in some other way unable to give)? In our study, we found that intentions mediated the effects of attitudes on behavior and no direct path resulted even when the criterion was the attempt to perform the behavior.

\section{Study 3}

Study 1 focused on statistical power. Study 2 scrutinized the reliability of measures of intentions and the specification of the intentions-behavior relation. In study 3 , we attempt to design an investigation to explore all the issues. To examine as optimally as possible the statistical power, reliability, and specification issues raised heretofore, a number of requirements had to be met.

First, consider the power issues. From study 1, it was learned that previous findings showing nonsignificant direct paths from attitudes to behavior were based generally on low levels of power and therefore were inconclusive. To increase power, one or more of three options are available: (a) increase the significance level (i.e., the type I error rate), (b) increase the magnitude of the minimum path that one would like to detect, and (c) increase the sample size. The 0.05 level of significance was maintained based on accepted practice. Similarly, the 0.2 path was retained because it yields a baseline that is practically meaningful, while corresponding to findings typical in the literature. Choosing a minimum greater than 0.2 might lead to premature rejection of valid models. We therefore chose to enhance the power of the test procedures by increasing the sample size. A sample of approximately 400 was selected. To give perspective, the sample sizes of the previous studies summarized in table 1 ranged from 93 to 533. 
Second, multiple measures of intentions were taken to correct for the unreliability in measures. With respect to the issue of the distinction between behavioral attempts and actual behavioral performances, we chose a context for research wherein failures to perform, given an attempt, were either unlikely or, if they occurred, tended to be random both within and across individuals. Failures to perform were either fairly likely or systematic in the studies discussed so far in this paper (e.g., with respect to giving blood, losing weight, drug usage, class attendance, coupon usage, securing a loan, getting a flu vaccination).

The behavior we chose for study was readership of seven popular business publications over a one-week period by MBA students. Pilot interviews indicated that MBA students are highly motivated to read business periodicals. They do this both because they identify strongly with the business world and keep up on happenings for self-image and conversational reasons and because they believe that success in course work sometimes depends on being well-informed on current business events. Nevertheless, due to heavy workloads, intense demands on time confront students with difficult choices. The typical student reads about three different periodicals, each on two or more occassions during any given week, with some students regularly monitoring four and five publications and only a rare individual never reading any. Given this context and with seven major periodicals to choose among (ranging from bi-monthly to weekly to daily publishing schedules), the reading behavior of each periodical is very much subject to volitional control. By focusing upon the number of times articles were read in each periodical individually over the one-week period, we were able to obtain seven interval-scaled dependent variables. Note that many of the studies discussed heretofore used measures of single behaviors expressed as dichotomies for the criterion.

The pilot interviews also revealed that social norms were either not a factor in people's readership decisions or else induced a reactivity in respondents. The insignificance of social norms found in the pilot interviews is also consistent with previous findings in similar behavioral domains such as class attendance and supplementary material readership among students (e.g., Bagozzi et al. 1988; Fredricks and Dossett 1983). The reactivity, which occurred infrequently, was manifest as a defense-like response to the social norm query such as 'I read [business periodicals] hecause I want to he informed ahout current financial matters or mergers and acquisitions' or 'I read [publications $x$ and $y$ ] 


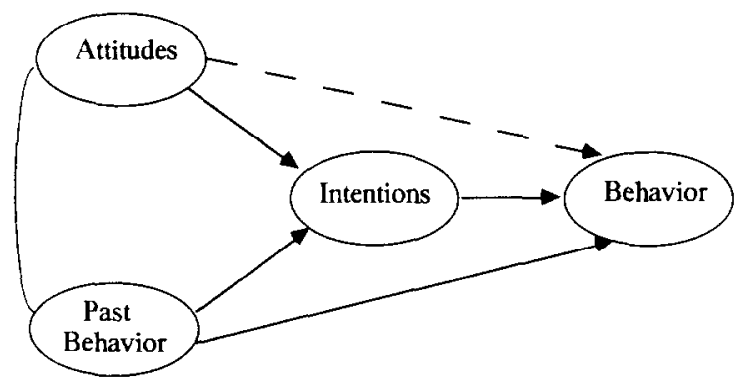

Fig. 2. Causal model for investigating magazine readership in study 3 (only latent variables are shown for simplicity).

for the pure enjoyment of it.' In any case, it appears that functional and attitudinal reactions drive readership and not social norms. Our pilot interviews suggested further that past behavior is a contributing factor to readership and therefore should be included as a covariate in the tests of hypotheses. Fig. 2 presents a schematic representation of the model used for testing hypotheses in study 3. See Bentler and Speckart (1979) for rationales for including past behavior as a covariate to influence intentions and behavior (e.g., Bagozzi 1981; McQuarrie and Langmeyer 1987).

\section{Method}

Respondents consisted of 390 MBA students who were asked to respond to 'a survey of magazine readership'. The left-hand column of table 3 lists the seven business publications and sample sizes for each. ${ }^{10}$ The questions asked addressed attitudes, intentions, past behavior, subscription practices and readership location for each of the seven periodicals. One week following the administration of the first questionnaire, a second was given asking for actual magazine readership in the previous week. Responses were recorded on a $7 \times 7$ matrix

10 The magazines were those most frequently mentioned in the pilot interviews. Only a few other magazines were mentioned (e.g., The Economist), but these were very specialized or not likely to be read by even a minority of the sample. Note in table 3 that the sample sizes range from 372-386, reflecting missing or incomplete data, except for Fortune magazine which had only a sample of 310. The smaller sample here resulted from a typing error on approximately 70 questionnaires wherein Forbes was mentioned twice in succession instead of the correct ordering of Forbes and Fortune. 
with days of the week at the top, the seven magazines listed in a column at the left, and yes-no in each cell. The study was begun at the beginning of the fourth week of the semester so as to be safely beyond the beginning of the semester which is typically hectic and yet be completed one to two weeks before mid-semester exams which also are disruptive of normal readership patterns.

Respondents were asked to write the last four digits of their student numbers (a 10-13 digit code) on the questionnaires. This was done to match up respondents across the two waves and to reinforce assurances of anonymity given on the questionnaires and verbally by the person administrating the questionnaires. Note also that the person whose name was on the questionnaires as sponsor of the research (i.e., the senior author) was neither an instructor of any of the students nor present at the time of administration. These steps should reduce any demand characteristics felt by subjects. Finally, the coding of responses was supervised by the senior author who then destroyed the four-digit codes once questionnaires were matched properly.

Approximately three weeks after administration of the second questionnaire, the senior author gave 30 minute debriefing lectures to MBA class sections outlining the general theory, past research, purpose of the study, and preliminary findings. Respondents were encouraged to contact the researcher at the close of the study for a full report, if they desired.

Two measures of attitude toward reading each current issue of the periodicals were taken. One scale consisted of the following statement: 'My attitude toward reading a current issue of [publication] during the upcoming week can be best expressed as...' A 5-point favorable/ unfavorable scale was used to record responses. The second attitude scale stated: "My feelings toward reading a current issue of [publication] during the upcoming week can be best expressed as ....' A 5-point pleasant/unpleasant scale was used to record responses. Prior to the elicitation of attitudinal responses, the following statement was contained on the questionnaire to circumscribe the domain of attitudes: 'For each of the following publications, indicate your personal reactions (note: by "reading a current issue," we mean "reading at least one article").'

Intentions were measured by asking respondents to express their 'intentions to read each publication' and 'plans to read each publication' during the upcoming week. Intentions were recorded on 5-point 
definitely do intend/definitely do not intend, and plans were recorded on 5-point definitely do plan/definitely do not plan items.

Past behavior for each publication was measured with 5-point items. The response alternatives were 'never', 'almost never', 'occasionally', 'frequently', and 'rarely miss an issue'.

As with the previous studies, the program LISREL and chi-square difference tests were used to test the significance of direct paths from attitudes to behavior. Power was again assessed using the procedure developed by Saris (Saris and Stronkhorst 1984; Satorra and Saris 1985), with $\alpha=0.05$ and 0.2 chosen as the critical value for the standardized path between attitudes and behavior.

\section{Results}

Before examining the tests of hypotheses, it is informative to view the findings for key causal paths (sec table 3). The direct path from attitudes to behavior (see column 1) is nonsignificant in all cases except for Business Week. We will return to these findings shortly. Next, as shown in column 2, intentions significantly influence behavior in all instances except for Business Week and the Harvard Business Review. ${ }^{11}$ Attitudes significantly affect intentions in all cases (see column 3). In sum, the results support the classic role for intentions as mediators of all the effects of attitudes on behavior.

Table 3 also presents the findings for the chi-square difference tests of the direct effects of attitudes on behavior. As shown in column 4 , the direct path is nonsignificant in all cases except for Business Week. The final column of table 3 displays the power of the procedures for detecting the direct path. The values for power range from moderate to high.

\section{Discussion}

On balance, the results establish that intentions mediate all the effects of attitudes on behavior. To demonstrate this, however, a

\footnotetext{
11 The nonsignificant path from intentions to behavior for the Harvard Business Review may be a consequence of the peculiar nature of this publication. Unlike the other publications which publish short, popular articles and do so frequently, the Harvard Business Review publishes longer and relatively more abstract, specialized, or technical articles on a bimonthly schedule. Sixty-eight per cent of the sample described themselves as nonreaders of the IIarvard Business Review, whereas nonreadership of the remaining periodicals ranged from $4 \%$ to $51 \%$.
} 
Table 3

Results for evaluating the mediating role of intentions (study 3 ).

\begin{tabular}{|c|c|c|c|c|c|}
\hline \multirow[t]{2}{*}{ Periodical } & \multicolumn{3}{|c|}{ Standardized rcgression weights } & \multicolumn{2}{|c|}{ Test of direct effects } \\
\hline & $\begin{array}{l}\text { Attitude } \\
\rightarrow \text { behavior }\end{array}$ & $\begin{array}{l}\text { Intention } \\
\rightarrow \text { behavior }\end{array}$ & $\begin{array}{l}\text { Attitude } \\
\rightarrow \text { intention }\end{array}$ & $x^{2}$-test & Power \\
\hline \multicolumn{6}{|c|}{ Business Week } \\
\hline$n=386$ & $0.22^{\mathrm{a}}$ & 0.08 & $0.44^{\mathrm{b}}$ & $\chi_{d}^{2}(1)=6.15^{a}$ & 0.55 \\
\hline \multicolumn{6}{|l|}{ Forbes } \\
\hline$n=381$ & 0.10 & $0.22^{a}$ & $0.37^{\mathrm{b}}$ & $\chi_{d}^{2}(1)=1.64$ & 0.59 \\
\hline \multicolumn{6}{|l|}{ Fortune } \\
\hline \multicolumn{6}{|l|}{ Harvard } \\
\hline \multicolumn{6}{|l|}{ Business } \\
\hline \multicolumn{6}{|l|}{ Review } \\
\hline$n=372$ & 0.09 & 0.02 & $0.30^{b}$ & $x_{d}^{2}(1)=1.62$ & 0.62 \\
\hline \multicolumn{6}{|l|}{ Local } \\
\hline \multicolumn{6}{|l|}{ Newspaper } \\
\hline$n=374$ & 0.01 & $0.25^{a}$ & $0.36^{\mathrm{b}}$ & $x_{d}^{2}(1)=0.03$ & 0.89 \\
\hline \multicolumn{6}{|l|}{ New York } \\
\hline $\begin{array}{l}\text { Times } \\
\quad n=376\end{array}$ & 0.02 & $0.29^{b}$ & $0.33^{b}$ & $\chi_{d}^{2}(1)=0.05$ & 0.68 \\
\hline Wall Street & & & & & \\
\hline Journal & & & & & \\
\hline$n=377$ & -.05 & $0.23^{\mathrm{a}}$ & $0.36^{b}$ & $\chi_{d}^{2}(1)=0.38$ & 0.78 \\
\hline
\end{tabular}

a $p \leq 0.05 ;{ }^{b} p \leq 0.01$

number of threats to internal validity had to be controlled. First, corrections were made for unreliability in the measures of intentions by use of latent variables with multiple indicators. Second, intentions were operationalized validly with volitions rather than with the often-used behavioral expectations measure. Third, care was taken to achieve the proper correspondence between measures of intentions and measures of behavior. Fourth, past reading practices for each publication were introduced as a control variable in each equation. Fifth, steps were taken to eliminate demand characteristics. Finally, all tests were performed under conditions of reasonably high power, thereby ensuring that our ability to detect an actual path from attitudes to behavior was satisfactory. In sum, the findings support the classic mediating role for intentions in the attitude-behavior relation (e.g., Ajzen and Fishbein 1980; Triandis 1977).

Intentions were found to fully mediate the impact of attitudes on behavior for six of the seven business periodicals. But why did attitudes 
directly influence behavior for Business Week? The nonsignificant path from intentions to behavior $(\gamma=0.08, t=0.87)$ suggests that readership of Business Week was not under volitional control. Further, the significant direct effect from past behavior to current behavior $(\gamma=0.33$, $t=4.3$, not shown in table) suggests that readership of Business Week was in response to habitual reactions, as well as the affective control due to attitudes. Apparently, readership of Business Week during the week in question was a more-or-less automatic reaction and not preplanned or thought-out in a volitional sense. The question remains why this was so.

'lo address this, we examined the data for Business Week in greater detail. We predicted that, if we investigated the decision processes of subscribers and nonsubscribers of Business Week separately, we would find that direct effects of attitudes on behavior should exist for subscribers but not for nonsubscribers; and intentions should affect behavior for nonsubscribers but not for subscribers. That is, we hypothesized that subscribers read largely for nonvolitional reasons and nonsubscribers read largely for volitional reasons. Our rationale is as follows. For subscribers, the opportunity to read the magazine is high because it is near at hand. Throughout the subscription period, the level of planning and effort needed to obtain the magazine is minimal. Moreover, ready accessibility should lead to some impulse reading over the course of the useful life of any issue which is about one week. At the same time, subscribers are likely to develop stylized routines and read the magazine regularly. This should result in some habitual patterns. In sum, subscribers are likely to read for nonvolitional reasons. But for nonsubscribers, the magazine is not very accessible, and rather involved decision processes must be undertaken each time one desires to read the magazine (e.g., plans must be made to buy an issue at the newsstand, borrow from a friend, or journey to the library). Therefore, volitional processes are likely to play a role for nonsubscribers.

As background, it should be noted that $54 \%$ of the total sample were subscribers to Business Week, the highest subscription rate among the seven periodicals. ${ }^{12}$ Given that Business Week has a higher percentage

\footnotetext{
12 The percentage of the total sample that subscribed to Forbes, Fortune, Harvard Business Review, cither of the two local newspapers, the Ncw York Times, and the Wall Strect Journal was $6 \%, 17 \% 2 \%, 36 \%, 5 \%$, and $50 \%$, respectively.
} 
of subscribers than the other periodicals, and generally much more so, it might be expected, based upon the aforementioned arguments, to find a direct effect from attitudes to behavior for Business Week but not for the other publications.

The findings supported our speculations. Readership by subscribers was indeed determined nonvolitionally. The direct effects of attitudes on behavior approached statistical significance $(\gamma=0.36, t=1.8)$; intentions did not determine behavior $(\gamma=-0.04, t=0.21)$; and past behavior influenced current behavior $(\gamma=0.20, t=2.1)$. In contrast, readership by nonsubscribers was a combination of volitional and nonvolitional causes. Attitudes did not directly affect behavior $(\gamma=$ $0.21, t=1.4)$; intentions tended to affect behavior $(\gamma=0.24, t=1.8)$; and past behavior influenced current behavior $(\gamma=0.23, t=2.3)$.

\section{General discussion}

The discovery of a direct effect from attitudes to behavior is a recent one, and researchers have not investigated systematically the conditions under which this effect does or does not occur. Among those studies testing for a direct effect, the findings are inconclusive because uncertainty exists as to whether volitional processes were indeed scrutinized, statistical power was high enough to detect small yet significant paths, reliability of measures of intentions was sufficiently high, and various other conceptual or methodological problems peculiar to individual studies could have obscured or falsely led one to observe direct effects. In addition to these issues, we raised questions dealing with the nature and length of the nomological network of instrumental acts between intentions and target behavior.

The findings showed that intentions can mediate all the effects of attitudes on behavior, but certain factors must be taken into account before this will occur. Unreliable measures of intentions can suggest direct effects of attitudes on hehaviors where such effects do not in reality exist. Indeed, common statistical inference procedures may be sensitive to small changes in reliability in this regard. On the other hand, misspecification of the linkages between intentions and behavior, such as omission of valid intervening instrumental acts, can lead to the opposite error: namely, the failure to detect a direct effect should one exist. 
In our study, we found that intentions do indeed mediate the effects of attitudes on intentions when the associations among latent variables are corrected for attenuation, and the correspondence between intentions and behavior is proper. Because the tests were conducted with moderate to high levels of statistical power, confidence in these findings is bolstered.

One weakness of our study should be mentioned. We employed self-reports to operationalize behavior, as have been in many previous studies (e.g., Belk 1985; Bentler and Speckart 1979). Such self-reports might have inflated the observed relationship between behavior and its antecedents such as attitudes and intentions in the direction of perceived cognitive consistency (Fredricks and Dossett 1983). More objective and unobtrusive measures of behavior should be used in future research (cf. Bagozzi et al. 1988).

The contexts of the studies both reviewed and conducted herein were natural settings, and no attempts were made to manipulate the role of intentions as mediators of the attitude-behavior relation. We would anticipate that it is possible to induce a valid direct effect of attitudes on behavior by controlling the appropriate conditions. For example, by interfering with the decision-making process or disrupting the formation of intentions, it is possible to observe that intentions are not well formed at the time of measurement. Or one can put a sufficient time interval between measurement and behavior so that differential stability of attitude and intentions may occur (Liska 1984). In such cases attitude might directly affect behavior. Alternatively, to the extent that decision making or intention formation can be stimulated or enhanced in some other way, attitudes should more strongly operate indirectly on behavior through volitional processes. In this regard, several questions arise. At what point in the decision processes are the intentions formed? How can one find out whether intentions are formed? In any case, the present studies show that a valid test of hypotheses must pay particular heed to reliability, statistical power, and proper specification of the intention-behavior relation.

\section{References}

Abelson, R.P., 1981. Psychological status of the seript coneept. American Psychologist 36 , $715-729$. 
Ajzen, I., 1985. 'From intentions to behavior: A theory of planned behavior'. In: J. Kuhl and J. Beckman (eds.), Action-control: From cognition to behavior. Heidelberg: Springer.

Ajzen, I. and M. Fishbein, 1977. Attitude-behavior relations: A theoretical analysis and review of empirical research. Psychological Bulletin 84, 888-918.

Ajzen, I. and M. Fishbein, 1980. Understanding attitudes and predicting social behavior. Englewood Cliffs, NJ: Prentice-Hall.

Bagozzi, R.P., 1981. Attitudes, intentions, and behavior: A test of some key hypotheses. Journal of Personality and Social Psychology 41, 607-627.

Bagozzi, R.P., 1982. A field investigation of causal relations among cognitions, affect, intentions, and behavior. Journal of Marketing Research 19, 562-583.

Bagozzi, R.P. and Y. Yi, 1988. On the evaluation of structural equation models. Journal of the Academy of Marketing Science 16, 74-94.

Bagozzi, R.P., Y. Yi and J. Baumgartner, 1988. The level of effort required for behavior as a moderator of the attitude-behavior relation. Unpublished working paper, The University of Michigan.

Belk, R.W., 1985. 'Issues in the intention-behavior discrepancy'. In: J.N. Sheth (ed.), Research in consumer behavior, Vol. 1. Greenwich, CT: JAI Press.

Bentler, P.M. and G. Speckart, 1979. Models of attitude-behavior relations. Psychological Review $86,452-464$.

Bentler, P.M. and G. Speckart, 1981. Attitudes 'cause' behaviors: A structural equation analysis. Journal of Personality and Social Psychology 40, 226-238.

Bettman, J.R., 1986. Consumer psychology. Annual Review of Psychology 37, 257-289.

Bonfield, E.H., 1974. Attitude, social influence, personal norm, and intention interactions as related to brand purchase behavior. Journal of Marketing Research 11, 379-389.

Engel, J.R., R.D. Blackwell and D.T. Kollat, 1978. Consumer behavior (3rd edition). Hillsdale, IL: The Dryden Press.

Fishbein, M. and I. Ajzen, 1975. Belief, attitude, intention and behavior: an introduction to theory and research. Reading, MA: Addison-Wesley.

Foxall, G., 1984. Evidence for attitudinal-behavioral consistency: Implications for consumer research. Journal of Economic Psychology 5, 7192.

Fredricks, A.J. and D.J. Dossett, 1983. Attitude-behavior relations: A comparison of the Fishbein-Ajzen and the Bentler-Speckart models. Journal of Personality and Social Psychology $45,501-512$.

Harrell, G.D. and P.D. Bennett, 1974. An evaluation of the expectancy value model of attitude measurement for physician prescribing behavior. Journal of Marketing Research 11, 269-278.

Howard, J.A., 1977. Consumer behavior: Application of theory. New York: McGraw-Hill.

Jöreskog, K. and D. Sörbom, 1984. LISREL VI: Analysis of linear structural relationships by the method of maximum likelihood. Mooresville, IN: Scientific Software.

Landis, D., H. Triandis and J. Adamopoulos, 1978. Habit and behavioral intentions as predictors of social behavior. The Journal of Social Psychology 106, 227-237.

Langer, E.J., 1978. 'Rethinking the role of thought in social interaction'. In: J.H. Harvey, W. Ickes and R.F. Kidd (eds.), New directions in attribution research, Vol. 2. New York: Halsted.

Liska, A.E., 1984. A critical examination of the causal structure of the Fishbein/Ajzen attitude-behavior model. Social Psychology Quarterly 47, 61-74.

Manstead, A.S.R., C. Proffitt and J.L. Smart, 1983. Predicting and understanding mothers' infant-feeding intentions and behavior: Testing the theory of reasoned action. Iournal of Personality and Social Psychology 44, 657-671.

McQuarrie, E.F. and D. Langmeyer, 1987. Planned and actual spending among owners of home computers. Journal of Economic Psychology 8, 141-159.

Oliver, R.L. and W.O. Bearden, 1985. Crossover effects in the theory of reasoned action: A moderating influence attempt. Journal of Consumer Research 12, 324-340. 
Oliver, R.L. and P.K. Berger, 1979. A path analysis of preventive health care decision models. Journal of Consumer Research 6, 113-122.

Roget's Thesaurus, 1966. New York: Dell Publishing.

Ryan, M.J. and E.H. Bonfield, 1980. Fishbein's intentions model: A test of external and pragmatic validity. Journal of Marketing 44, 82-95.

Saris, W.E. and L.H. Stronkhorst, 1984. Causal modeling in nonexperimental research. Amsterdam: Sociometric Research Foundation.

Satorra, A., and W.E. Saris, 1985. Power of the likelihood ratio test in covariance structure analysis. Psychometrika 50, 83-90.

Shimp, T.A. and A. Kavas, 1984. The theory of reasoned action applied to coupon usage. Journal of Consumer Research 11, 795-809.

Triandis, H.C., 1977. Interpersonal behavior. Monterey, CA: Brooks/Cole.

Verhallen, T.M.M. and R. Pieters, 1984. Attitude theory and behavioral costs. Journal of Economic Psychology 5, 223-249.

Webster's New Collegiate Dictionary, 1980. Springfield, MA: G\&C Merriam Company.

Zuckerman, M. and H.T. Reis, 1978. Comparison of three models for predicting altruistic behavior. Journal of Personality and Social Psychology 36, 498-510. 